\title{
Relative validity and reliability of an FFQ in youth with type 1 diabetes
}

\author{
Angela D Liese ${ }^{1, *}$, Jamie L Crandell ${ }^{2}$, Janet A Tooze ${ }^{3}$, Mary T Fangman ${ }^{4}$, Sarah C Couch ${ }^{5}$, \\ Anwar T Merchant ${ }^{1}$, Ronny A Bell ${ }^{6}$ and Elizabeth J Mayer-Davis ${ }^{4}$ \\ 'Department of Epidemiology and Biostatistics and Center for Research in Nutrition and Health Disparities, Arnold \\ School of Public Health, University of South Carolina, 915 Greene Street, Columbia, SC 29208, USA: ${ }^{2}$ School of \\ Nursing and Department of Biostatistics, University of North Carolina, Chapel Hill, NC, USA: ${ }^{3}$ Department of \\ Biostatistical Sciences, Wake Forest School of Medicine, Winston-Salem, NC, USA: ${ }^{4}$ Department of Nutrition and \\ Department of Medicine, University of North Carolina, Chapel Hill, NC, USA: ${ }^{5}$ Department of Nutritional Sciences, \\ University of Cincinnati Medical Center, Cincinnati, OH, USA: ${ }^{6}$ Department of Epidemiology and Prevention, Wake \\ Forest School of Medicine, Winston-Salem, NC, USA
}

Submitted 21 May 2013: Final revision received 30 January 2014: Accepted 7 February 2014: First published online 28 March 2014

\begin{abstract}
Objective: To evaluate the relative validity and reliability of the SEARCH FFQ that was modified from the Block Kids Questionnaire.

Design: Study participants completed the eighty-five-item FFQ twice plus three $24 \mathrm{~h}$ dietary recalls within one month. We estimated correlations between frequencies obtained from participants with the true usual intake for food groups and nutrients, using a two-part model for episodically consumed foods and measurement error adjustment.

Setting: The multi-centre SEARCH for Diabetes in Youth Nutrition Ancillary Study. Subjects: A subgroup of 172 participants aged 10-24 years with type 1 diabetes. Results: The mean correlations, adjusted for measurement error, of food groups and nutrients between the FFQ and true usual intake were 0.41 and 0.38 , respectively, with $57 \%$ of food groups and $70 \%$ of nutrients exhibiting correlations $>0 \cdot 35$. Correlations were high for low-fat dairy $(0 \cdot 80)$, sugar-sweetened beverages $(0.54)$, cholesterol $(0.59)$ and saturated fat $(0.51)$, while correlations were poor for high-fibre bread and cereal $(0 \cdot 16)$ and folate $(0 \cdot 11)$. Reliability of FFQ intake based on two FFQ administrations was also reasonable, with $54 \%$ of Pearson correlation coefficients $\geq 0 \cdot 5$. Reliability was high for low-fat dairy $(0 \cdot 7)$, vegetables $(0 \cdot 6)$, carbohydrates, fibre, folate and vitamin C (all 0.5), but less than desirable for lowfat poultry and high-fibre bread, cereal, rice and pasta $(0 \cdot 2-0 \cdot 3)$.

Conclusions: While there is some room for improvement, our findings suggest that the SEARCH FFQ performs quite well for the assessment of many nutrients and food groups in a sample of youth with type 1 diabetes.
\end{abstract}

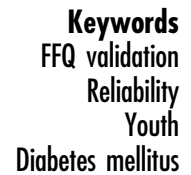

Type 1 diabetes is one of the leading chronic conditions in youth $^{(1)}$. The incidence of type 1 diabetes is increasing worldwide at roughly $2-3 \%$ per year, as has recently been confirmed among non-Hispanic white youth in the USA by the SEARCH for Diabetes in Youth Study $(\mathrm{SEARCH})^{(1-4)}$. Even though medical nutritional therapy is one of the four cornerstones of care for youth with type 1 diabetes $^{(5)}$, this group falls markedly short of reaching the current dietary recommendations ${ }^{(6)}$. Thus, while obesity has traditionally not been a part of the classical type 1 diabetes presentation, today obesity in youth with type 1 diabetes is as common if not more common than in youth without diabetes $^{(7)}$.
Over the past decades, nutritional epidemiology has increasingly focused on foods, food groups and dietary patterns, in addition to consideration of nutrients. While the earlier validation literature for FFQ focused largely on nutrients and energy intake ${ }^{(8-10)}$, more recent validation efforts have included foods and food groups ${ }^{(11)}$. Furthermore, while measurement error correction methods for dietary data have a longstanding tradition ${ }^{(12-15)}$, consideration of these methods in validations of FFQ has become more prominent ${ }^{(16-21)}$. Moreover, statistical methodology has been developed to the point of addressing the underlying complexities in appropriately analysing the validity of food and food group data ${ }^{(21-23)}$. 
Researchers at the National Cancer Institute (NCI) and elsewhere have developed a measurement error model for episodically consumed dietary components that also accommodates daily consumed dietary components, termed the NCI method ${ }^{(22,23)}$. This method fits a two-part measurement error model to appropriately model episodically consumed foods, and models the correlations between the probability of consuming a dietary component on a given day and the consumption day amount. An extension of this method models energy as a 'third part' of the model to provide energy-adjusted estimates ${ }^{(21,24)}$

Motivated by the need to investigate the role of dietary intake on the development of acute and long-term complications of diabetes in youth ${ }^{(4)}$, the SEARCH Nutrition Ancillary Study (SNAS) was designed to take advantage of recent developments in dietary assessment and measurement error adjustment methodology by incorporating a diet assessment sub-study. At the inception of SEARCH in 2000, few validated FFQ existed for studies of youth, with the Block Kids Questionnaire and the Youth/Adolescent Questionnaire being notable exceptions ${ }^{(16,25)}$. SEARCH developed an FFQ based on the Block Kids Questionnaire $^{(6)}$, but made a number of substantive changes, including an expanded list of foods to reflect the ethnic, cultural and regional diversity of the SEARCH population and a portion size visual, which is why we refer to it as the SEARCH FFQ. Neither the original Block Kids Questionnaire nor the SEARCH FFQ has been evaluated in youth with diabetes. The purpose of the present study was to evaluate the relative validity and reliability of the SEARCH FFQ to assess food groups and nutrients in a subpopulation of youth with type 1 diabetes aged 10 years and older enrolled in SNAS between 2008 and 2011, using the NCI method.

\section{Methods}

\section{Study design and sample}

SEARCH is a multi-centre study that began conducting population-based ascertainment of non-gestational cases of diagnosed diabetes in youth less than 20 years of age in 2001 and 2009 for prevalent cases, and continues with ascertainment of incident cases from 2002 through the present ${ }^{(4)}$. Details of the methods have been published. The protocol was compliant with the Health Insurance Portability and Accountability Act and approved by the local institutional review boards. Youth with diabetes identified by the SEARCH surveillance effort completed a brief survey. Those whose diabetes was not secondary to other health conditions were invited to the study visit involving questionnaires, physical examinations and laboratory measurements. Ascertainment was conducted using a network of health-care providers including paediatric endocrinologists, hospitals and other providers. Case reports were validated through physician reports, medical record reviews or, in a few instances, self-report of a physician's diagnosis of diabetes. Diabetes type, as assigned by the health-care provider, was categorized as type 1, type 2 and other type (including hybrid type, maturity onset of diabetes in youth, type designated as 'other', type unknown by the reporting source and missing).

The SNAS was designed to examine the associations of nutritional factors with the progression of insulin secretion defects and the presence of CVD risk factors in youth with type 1 diabetes. The SNAS protocol was reviewed and approved by the institutional review boards of all participating institutions. SNAS did not recruit additional participants, but collected data on infant feeding and nutrient biomarkers from youth enrolled in SEARCH. The SNAS Diet Assessment Sub-study (DAS) was designed to validate the FFQ and correct for measurement error in analyses of dietary intake-disease outcome relationships in the larger SEARCH or SNAS samples. DAS enrolled 172 SEARCH participants aged 10-24 years proportionately from the six SEARCH sites to complete two FFQ one month apart and three $24 \mathrm{~h}$ dietary recalls by telephone in the interim.

\section{Dietary assessment}

The FFQ used by SEARCH (available upon request) was modified from the Block Kids Questionnaire with an expanded list of foods selected to consider ethnic, cultural and regional diversity ${ }^{(6)}$. The FFQ was generally completed by the youth without assistance after receiving staff instruction. It consisted of eighty-five food lines for which the participant indicates if the item(s) was/were consumed in the past week ('yes/no') and if yes, on how many days and the average portion size. Portion size was queried either as a number (e.g. number of slices of bread) or as very small, small, medium and large relative to pictures of food in bowls or plates provided with the form. An openended question at the end of the FFQ queried other foods that a participant might want to report. The nutrient and portion size databases for this instrument were modified from the respective Diabetes Prevention Program databases, using the Nutrition Data System for Research (NDSR; Nutrition Coordinating Center, University of Minnesota, Minneapolis, MN, USA; database version 2.6/ $8 \mathrm{~A} / 23$ ) and industry sources.

The previous-day $24 \mathrm{~h}$ recalls were conducted by trained and certified staff of the University of North Carolina Nutrition Obesity Research Center - Diet, Physical Activity and Body Composition Core. The interviews were conducted by telephone on randomly selected, nonconsecutive days including two weekdays and one weekend day during a four-week sampling window. NDSR version 2008 and 2009 software licensed from the Nutrition Coordinating Center at the University of Minnesota was employed, using the multi-pass approach in which a participant was first asked to provide a general listing of foods consumed on the previous day, starting 
with the first food consumed after awakening and ending with the last food consumed before sleep, and grouped by eating episode. Subsequently, the interviewing dietitian reviewed the list with the participant and prompted for foods or eating episodes forgotten or omitted, queried for more detail on the time, name and location of the eating episodes, collected details on the foods reported including quantity and portion size, verified the information and prompted for any omissions.

The 166 individual foods that were ascertained from the $24 \mathrm{~h}$ recalls with the NDSR system were grouped into twenty-seven specific food groups. A total of twenty-seven corresponding food groups were created from the eightyfive lines of the FFQ by either collapsing food lines based on their major components or by disaggregating composite foods into constituent foods with the goal of having as similar a composition of the food groups in the FFQ and the $24 \mathrm{~h}$ recall. To be able to compare our findings with other published studies, we also created a number of broad food groups such as all fruit and all vegetables. If the portion size units differed between the $24 \mathrm{~h}$ recall and the FFQ, appropriate conversions were made to the FFQ data.

\section{Statistical analyses}

The most commonly used approach in the past to assessing FFQ validity was to examine the Pearson's correlation between the FFQ and the reference method, i.e. the $24 \mathrm{~h}$ recalls, which is presented here for the sake of comparability. This approach does not account for measurement error and assumes that the variables obtained from the FFQ and $24 \mathrm{~h}$ recalls are continuous, an assumption that is violated for infrequently consumed foods. In fact, many of the studied food groups are consumed infrequently, so that there is a mass of zeroes in the distribution of the $24 \mathrm{~h}$ recall data.

To appropriately account for measurement error and these semi-continuous data we follow Midthune et al. ${ }^{(21)}$, who use the NCI method to estimate the correlation between FFQ intake $\left(Q_{i}\right)$ and true usual intake $\left(T_{i}\right)$ for an individual $i$, briefly described below. The SAS macro and more details can be found elsewhere (http://appliedresearch. cancer.gov/diet/usualintakes/macros.html). We let $p_{i}$ be the true probability to consume on a given day, $A_{i}$ be the true average amount consumed on a consumption day and $T_{i}=p_{i} \times A_{i}$ be the true usual intake of the episodically consumed food. The daily intake for day $j$ from the reference instrument, the $24 \mathrm{~h}$ recall, is designated $R_{i j}$. For this method, we assume that the reported $24 \mathrm{~h}$ recall intakes are unbiased estimates of true average daily intake ${ }^{(21)}$. In particular, we assume that any food reported on the $24 \mathrm{~h}$ recall was actually consumed, that any food that was consumed was reported on the $24 \mathrm{~h}$ recall and that the usual intake from the $24 \mathrm{~h}$ recall on a consumption day is equal to $A_{i}$ plus random error (primarily due to dayto-day variation); therefore the mean of the $R_{i j}$ equals $T_{i}$.
The NCI method models jointly the probability of intake on a given day and, for days on which consumption occurs, the intake amount using the two-part model:

$$
\operatorname{logit}\left(p_{i}\right)=\beta_{10}+\beta_{11} Q_{i}+u_{1 i}
$$

and

$$
\left(R_{i j}^{*} \mid R_{i j}>0\right)=\beta_{20}+\beta_{21} Q_{i}^{*}+u_{2 i}+\varepsilon_{2 i j}
$$

where $u_{1 i}$ and $u_{2 i}$ are person-specific random effects that have a bivariate normal distribution that are independent of the within-person random error, $\varepsilon_{2 i j}$. The asterisks indicate that $R_{i j}$ and $Q_{i}$ are evaluated on a Box-Cox transformed scale.

Then, the true mean daily consumption $\left(T_{i}\right)$ is predicted for each participant as a function of $Q_{i}, u_{1 i}$ and $u_{2 i}$, using the Monte Carlo method to generate the distribution of $T_{i}$ and $Q_{i}$. For detecting diet-disease relationships, the key statistics estimated are the correlation coefficient between $T_{i}$ and $Q_{i}$ and the attenuation factor, which is the slope in the regression of $T_{i} v . Q_{i}$. Although the NCI method was designed for episodically consumed foods, it can be applied to nutrients and daily consumed foods by constraining the consumption probability to be equal to 1 . This constraint was applied to all nutrients/foods where consumption was reported on greater than $90 \%$ of days.

We estimated the correlation coefficients and attenuation factors twice, without adjustment for energy and with energy adjustment, as described in Midthune et al. ${ }^{(21)}$. Briefly, energy adjustment involves using the NCI method to jointly model usual intake of the food group or nutrient and usual intake of energy, then using the Monte Carlo method to generate $T_{i}$ and $Q_{i}$ for pseudo-individuals. From the Monte Carlo estimated distributions, energy-adjusted usual intake and energy-adjusted FFQ intake were estimated using the residual method. The residuals were then used to compute the correlation coefficients and attenuation factors. For nutrient densities the ratio of usual intakes to energy intake was used ${ }^{(24)}$. Standard errors of the correlation and attenuation coefficients were computed as the standard deviations across 100 Monte Carlo samples of usual intake. The attenuation factor was estimated from the measurement error model (with and without adjustment for energy) and quantifies the amount of bias (attenuation) that would apply to the regression coefficient of a specific food group/nutrient-disease relationship. It is a multiplicative factor; thus, the smaller the factor the greater the attenuation of the relative risk estimate. Foods for which consumption was reported on fewer than $90 \%$ of the $24 \mathrm{~h}$ recalls were defined as episodically consumed and modelled accordingly.

Test-retest reliability of this FFQ was assessed in the 148 participants who completed both FFQ as part of the SNAS DAS. Reliability coefficients were estimated using intraclass correlation after Box-Cox transforming FFQ reported intakes to improve normality. All analyses were done using the statistical software package SAS version 9.2. 


\section{Results}

Of the 172 participants enrolled in the DAS, fifteen were excluded because they were missing one or more $24 \mathrm{~h}$ recalls ( $n$ 15; seven had only one $24 \mathrm{~h}$ recall and eight had two). The analysis sample included 157 participants who completed the first FFQ and all three $24 \mathrm{~h}$ recalls and could be used to assess the validity of the FFQ. The included participants were similar to those excluded in terms of race, age and gender. Of the analysis sample, $51 \%$ were male, $74 \%$ were Non-Hispanic white, 15\% African American and $11 \%$ of other minority race/ethnic group. The mean age was 16 years (range: $10-24$ years) and the average duration of diabetes was $5 \cdot 8$ years (range: $0 \cdot 5-7 \cdot 8$ years).

Presented in Table 1 are the mean intakes for the food groups for participants reporting any consumption level, as assessed by both the FFQ and the three $24 \mathrm{~h}$ recalls. Intakes were generally higher on the $24 \mathrm{~h}$ recalls than on the FFQ with the exception of meat, nuts and seeds, and fats and oils. Additionally, the percentage of the sample reporting any consumption is shown. Mean energy and nutrient intakes for the sample are shown in Table 2 according to dietary assessment instrument. Intake estimates from $24 \mathrm{~h}$ recalls were mostly, but not always, higher than those from the FFQ.

Estimates of the correlation between the true usual intake and FFQ-reported intakes and the corresponding attenuation factors are shown in Table 3, first as crude Pearson's correlations (for comparison with the literature) and then as measurement error-adjusted coefficients with and without energy adjustment. Use of the measurement error model resulted in a strengthening of correlations. Without consideration of energy intake, the measurement

Table 1 Consumption of foods groups (servings/d) as assessed by FFQ and $24 \mathrm{~h}$ dietary recalls ( $n$ 157); youth aged 10-24 years with type 1 diabetes, SEARCH for Diabetes in Youth Nutrition Ancillary Study

\begin{tabular}{|c|c|c|c|c|c|c|}
\hline \multirow[b]{2}{*}{ Food group } & \multicolumn{3}{|c|}{ Assessed by FFQ } & \multicolumn{3}{|c|}{ Assessed by $24 \mathrm{~h}$ recall } \\
\hline & $\begin{array}{c}\% \\
\text { Consuming }\end{array}$ & $\begin{array}{l}\text { Mean servings among } \\
\text { those who consumed }\end{array}$ & SD & $\begin{array}{l}\% \text { Recalls with } \\
\text { any consumption }\end{array}$ & $\begin{array}{l}\text { Mean servings on } \\
\text { consumption days }\end{array}$ & SD \\
\hline $\begin{array}{l}\text { All Bread, Cereal, Rice and } \\
\text { Pasta }\end{array}$ & 100 & $2 \cdot 6$ & $1 \cdot 3$ & 98 & $5 \cdot 8$ & $3 \cdot 4$ \\
\hline $\begin{array}{l}\text { Bread, cereal, rice and pasta } \\
\text { (high fibre) }\end{array}$ & 22 & 0.3 & 0.2 & 31 & $2 \cdot 3$ & 1.6 \\
\hline $\begin{array}{l}\text { Bread, cereal, rice and pasta } \\
\text { (low fibre) }\end{array}$ & 100 & $2 \cdot 5$ & 1.3 & 95 & $5 \cdot 3$ & $3 \cdot 3$ \\
\hline All Fruits and Vegetables & 100 & $3 \cdot 3$ & $2 \cdot 0$ & 93 & 3.2 & $2 \cdot 6$ \\
\hline All Vegetables & 100 & 1.7 & $1 \cdot 3$ & 88 & $2 \cdot 3$ & $2 \cdot 1$ \\
\hline Vegetable (tomato) & 99 & 0.2 & 0.2 & 54 & 0.8 & 0.8 \\
\hline $\begin{array}{l}\text { Vegetable (dark green, } \\
\text { cruciferous) }\end{array}$ & 96 & $0 . \overline{5}$ & $0 \cdot 7$ & 18 & $1 \cdot 3$ & $1 \cdot 8$ \\
\hline Vegetable (deep yellow) & 91 & 0.2 & 0.3 & 22 & 0.5 & 0.8 \\
\hline Vegetable (potatoes) & 93 & 0.5 & 0.5 & 31 & 1.7 & $1 \cdot 2$ \\
\hline Vegetable (other) & 99 & 0.4 & 0.4 & 69 & 1.0 & $1 \cdot \overline{1}$ \\
\hline All Fruit & 97 & 1.6 & 1.3 & 50 & 1.9 & 1.8 \\
\hline Fruit and fruit juice (citrus) & 73 & 0.5 & 0.7 & 21 & $1 \cdot 2$ & 1.7 \\
\hline Fruit and fruit juice (other) & 95 & 1.2 & 1.0 & 39 & 1.8 & 1.4 \\
\hline All Dairy & 100 & $2 \cdot 0$ & 1.3 & 93 & 2.5 & $2 \cdot 1$ \\
\hline Dairy (low fat) & 94 & $1 \cdot 2$ & 1.0 & 72 & 1.6 & 1.4 \\
\hline Dairy (high fat) & 100 & 0.9 & 0.7 & 76 & 1.5 & 1.8 \\
\hline $\begin{array}{l}\text { All Meat, Fish, Poultry, Eggs } \\
\text { and Beans }\end{array}$ & 100 & 2.5 & 1.5 & 94 & $2 \cdot 2$ & 1.8 \\
\hline $\begin{array}{l}\text { Meat (beef, pork, non-poultry } \\
\text { lunch meat) }\end{array}$ & 100 & 1.4 & 1.0 & 77 & $1 \cdot 2$ & $1 \cdot 1$ \\
\hline Poultry (all) & 89 & 0.5 & 0.5 & 40 & $1 \cdot 1$ & 0.9 \\
\hline Poultry (high fat) & 85 & 0.4 & 0.5 & 14 & 1.4 & 0.9 \\
\hline Poultry (low fat) & 46 & 0.2 & 0.1 & 29 & 0.9 & 0.7 \\
\hline Fish and other seafood & 56 & 0.2 & 0.2 & 3 & 1.3 & 0.8 \\
\hline Beans (dried) & 78 & 0.2 & 0.4 & 15 & 1.0 & 0.9 \\
\hline Eggs & 96 & 0.4 & 0.4 & 26 & 1.6 & 1.3 \\
\hline Nuts and seeds & 57 & $2 \cdot 0$ & $2 \cdot 4$ & 22 & 0.7 & 0.8 \\
\hline Fats, Oils and Sweets & 100 & $4 \cdot 3$ & $2 \cdot 8$ & 98 & 3.0 & $2 \cdot 3$ \\
\hline Fats and oils & 100 & $3 \cdot 0$ & $2 \cdot 3$ & 93 & 1.6 & $1 \cdot 3$ \\
\hline Sweets and desserts & 100 & 1.3 & 0.9 & 75 & $2 \cdot 0$ & 1.9 \\
\hline $\begin{array}{l}\text { All Chips, Crackers, Popcorn, } \\
\text { Pretzels }\end{array}$ & 92 & $0 \cdot 7$ & 0.5 & 39 & $2 \cdot 1$ & 1.6 \\
\hline $\begin{array}{l}\text { Chips, crackers (high fat) } \\
\text { and popcorn }\end{array}$ & 87 & 0.4 & 0.4 & 30 & $2 \cdot 1$ & 1.5 \\
\hline Soda, Fruit Flavour Drink & 61 & $1 \cdot 2$ & $1 \cdot 2$ & 23 & 1.9 & 1.4 \\
\hline
\end{tabular}

Of the food groups listed above, three (high-fat poultry, fish and other seafood, dried beans) are shown here for completeness sake but will not be considered in further analyses because they had fewer than twenty people with at least two consumption days on the $24 \mathrm{~h}$ recall. 
Table 2 Mean daily nutrient consumption assessed by FFQ and $24 \mathrm{~h}$ dietary recalls, with standard deviations $(n 157)$; youth aged 10-24 years with type 1 diabetes, SEARCH for Diabetes in Youth Nutrition Ancillary Study

\begin{tabular}{|c|c|c|c|c|}
\hline \multirow[b]{2}{*}{ Nutrient } & \multicolumn{2}{|c|}{ Assessed by FFQ } & \multicolumn{2}{|c|}{ Assessed by $24 \mathrm{~h}$ recall } \\
\hline & Mean & SD & Mean across days & SD \\
\hline Total energy (kJ) & 6950 & 2920 & 8330 & 3276 \\
\hline Total energy (kcal) & 1661 & 698 & 1991 & 783 \\
\hline$\%$ Energy from carbohydrate & 46 & 8 & 48 & 11 \\
\hline Total carbohydrate $(\mathrm{g})$ & 193.1 & $90 \cdot 3$ & 237.7 & 99.8 \\
\hline Starch $(g)$ & $82 \cdot 2$ & 38.5 & 118.6 & $54 \cdot 1$ \\
\hline Fructose (g) & $22 \cdot 5$ & $18 \cdot 0$ & $17 \cdot 1$ & $17 \cdot 2$ \\
\hline$\%$ Energy from protein & 15 & 3 & 17 & 5 \\
\hline Total protein $(\mathrm{g})$ & $63 \cdot 2$ & $28 \cdot 2$ & 81.5 & 38.1 \\
\hline$\%$ Energy from fat & 40 & 6 & 36 & 8 \\
\hline Total fat $(\mathrm{g})$ & $73 \cdot 1$ & 31.9 & $81 \cdot 2$ & $40 \cdot 3$ \\
\hline$\%$ Energy from SFA & 14 & 3 & 12 & 4 \\
\hline Saturated fat $(\mathrm{g})$ & $25 \cdot 3$ & 11.4 & 27.9 & $15 \cdot 3$ \\
\hline Fibre $(\mathrm{g})$ & $12 \cdot 4$ & $6 \cdot 2$ & 14.6 & 8.5 \\
\hline $\mathrm{Ca}(\mathrm{mg})$ & $713 \cdot 6$ & 445.6 & $1059 \cdot 7$ & $609 \cdot 2$ \\
\hline $\mathrm{Mg}(\mathrm{mg})$ & $208 \cdot 3$ & 97.4 & $252 \cdot 1$ & 113.5 \\
\hline Cholesterol (mg) & $245 \cdot 6$ & $142 \cdot 0$ & 271.6 & 248.4 \\
\hline $\mathrm{Fe}(\mathrm{mg})$ & 11.4 & 5.5 & $16 \cdot 2$ & 8.8 \\
\hline Dietary folate equivalents $(\mu \mathrm{g})$ & $370 \cdot 1$ & $175 \cdot 3$ & $613 \cdot 6$ & 421.9 \\
\hline Vitamin C (mg) & 78.2 & $57 \cdot 7$ & 65.4 & 77.5 \\
\hline Linoleic acid (g) & $10 \cdot 4$ & $5 \cdot 2$ & $15 \cdot 6$ & $10 \cdot 1$ \\
\hline Linolenic acid (g) & $1 \cdot 0$ & 0.5 & 1.6 & 1.3 \\
\hline
\end{tabular}

error-adjusted correlation for the food groups ranged from high ( $\rho=0.80$ for low-fat dairy) to very low (chips, high-fat crackers and popcorn; low fat-poultry; high-fibre bread, cereal, rice and pasta: all $\rho<0 \cdot 20)$, with sixteen of twentyeight food groups ( $57 \%$ ) exhibiting correlations $\rho>0.35$. Validity estimates were quite high for several food groups typically recommended for youth with type 1 diabetes, such as low-fat dairy $(\rho=0 \cdot 80)$, vegetables $(\rho=0 \cdot 48)$ and foods typically to be avoided, such as soda $(\rho=0.54)$ or sweets and deserts $(\rho=0 \cdot 51)$. Additional adjustment for total energy within the measurement error model did not have a strong impact on the correlation coefficients for most food groups, the exceptions being fats and oils, meat and high-fat dairy. This may be because misreporting in these food groups may not be proportional to energy intake. The mean measurement error-adjusted correlation coefficient was $\rho=0.41$ for all food groups without consideration of energy intake and $\rho=0.39$ after consideration of total energy.

The correlations for the nutrients ranged from 0.59 for cholesterol to 0.11 for dietary folate, with fourteen of twenty nutrients (70\%) exhibiting correlation coefficients $\rho>0.35$ in the measurement error-adjusted but not the energy-adjusted model. For example, validity statistics for energy $(\rho=0.42)$, protein $(\rho=0.38)$, total fat $(\rho=0.48)$ and saturated fat $(\rho=0.51)$ were quite good. A total of eleven of nineteen nutrients (58\%) exhibited energy-adjusted correlation coefficients $\rho>0 \cdot 35$. In summary, the mean measurement error-adjusted correlation coefficient was $\rho=0.38$ for all nutrients and $\rho=0.37$ adjusted additionally for energy intake. Adjustment for total energy impacted most nutrients. Additional subgroup analyses (data not shown) revealed that correlation coefficients were slightly higher for youth aged 15 years and older (mean measurement error- and energy-adjusted correlation for foods $\rho=0.47$ and $\rho=0.37$ for nutrients) compared with those under 15 years of age ( $\rho=0.44$ and $\rho=0 \cdot 35$, respectively).

Shown also in Table 3 are the attenuation factors for each food group and nutrient. The average of the attenuation factors (non-energy adjusted) was $\lambda=0.29$ for food groups ( $\lambda=0.25$ adjusted for energy) and $\lambda=0.27$ for nutrients $(\lambda=0.31$ adjusted for energy). Energy-adjusted attenuation factors ranged from $\lambda=0.53$ for low-fat dairy to $\lambda=-0.03$ for chips, high-fat crackers and popcorn. The negative attenuation and correlation for chips, high-fat crackers and popcorn indicate a weak relationship between the FFQ and true usual intake. For nutrients, attenuation factors ranged from $\lambda=0.64$ for cholesterol to $\lambda=0.13$ for vitamin C.

Reliability statistics for the FFQ are shown in Table 4. Average intake in the entire sample (including both consumers and non-consumers) was slightly higher for most food groups and nutrients at the first compared with the second administration of the FFQ. Intra-class correlation coefficients ranged from $0 \cdot 24$ for high-fibre bread, cereal, rice and pasta to 0.64 for all dairy and 0.71 for low-fat dairy.

\section{Discussion}

The literature on validity and reliability of dietary assessment methods in youth was reviewed by McPherson et al. in $2000^{(26)}$. In addition to the SEARCH FFQ, there are still 
Table 3 Estimates of the correlation between true and FFQ-reported intakes $\left(\rho_{\mathrm{QT}}\right)$ and the attenuation factor $\left(\lambda_{\mathrm{QT}}\right)$, with standard errors, in the model adjusted for measurement error (ME) and the model adjusted for both ME and energy ( $n$ 157); youth aged 10-24 years with type 1 diabetes, SEARCH for Diabetes in Youth Nutrition Ancillary Study

\begin{tabular}{|c|c|c|c|c|c|c|c|c|c|}
\hline & \multirow[b]{2}{*}{ Pearson's $\rho$} & \multicolumn{4}{|c|}{ ME adjusted } & \multicolumn{4}{|c|}{ ME and energy adjusted } \\
\hline & & $\rho_{\mathrm{QT}}$ & SE & $\lambda_{\mathrm{QT}}$ & SE & $\rho_{\text {QT }}$ & SE & $\lambda_{\mathrm{QT}}$ & SE \\
\hline \multicolumn{10}{|l|}{ Food group } \\
\hline All Bread, Cereal, Rice and Pasta & 0.15 & 0.21 & 0.08 & 0.15 & 0.06 & 0.26 & 0.07 & 0.18 & 0.05 \\
\hline Bread, cereal, rice and pasta (high fibre)† & 0.06 & 0.16 & 0.07 & 0.19 & 0.08 & 0.12 & 0.07 & 0.12 & 0.07 \\
\hline Bread, cereal, rice, and pasta (low fibre) & 0.17 & 0.25 & 0.08 & 0.19 & 0.06 & 0.30 & 0.07 & 0.23 & 0.06 \\
\hline All Fruits and Vegetables & 0.22 & 0.45 & 0.06 & 0.29 & 0.05 & 0.41 & 0.06 & 0.30 & 0.05 \\
\hline All Vegetables & 0.24 & 0.48 & 0.06 & 0.32 & 0.05 & 0.56 & 0.04 & 0.37 & 0.04 \\
\hline Vegetable (tomato)† & 0.15 & 0.32 & 0.07 & 0.24 & 0.05 & 0.27 & 0.07 & 0.15 & 0.04 \\
\hline Vegetable (dark green, cruciferous) $†$ & 0.04 & 0.27 & 0.08 & $0 \cdot 19$ & 0.06 & 0.36 & 0.06 & 0.19 & 0.04 \\
\hline Vegetable (deep yellow)t & 0.56 & 0.67 & 0.05 & 0.53 & 0.05 & 0.72 & 0.03 & 0.49 & 0.03 \\
\hline Vegetable (potatoes) $\dagger$ & 0.34 & 0.57 & 0.05 & 0.47 & 0.05 & 0.60 & 0.04 & 0.33 & 0.03 \\
\hline Vegetable (other)† & 0.27 & 0.53 & 0.05 & 0.42 & 0.05 & 0.51 & 0.05 & 0.36 & 0.04 \\
\hline All Fruitt & 0.18 & 0.34 & 0.06 & 0.23 & 0.05 & 0.33 & 0.06 & 0.20 & 0.04 \\
\hline Fruit and fruit juice (citrus)† & 0.24 & 0.39 & 0.07 & 0.22 & 0.04 & 0.31 & 0.07 & 0.18 & 0.04 \\
\hline Fruit and fruit juice (other) & 0.18 & 0.31 & 0.06 & 0.23 & 0.05 & 0.34 & 0.07 & 0.21 & 0.05 \\
\hline All Dairyt & 0.47 & 0.67 & 0.04 & 0.57 & 0.05 & 0.63 & 0.04 & 0.57 & 0.05 \\
\hline Dairy (low fat)t & 0.60 & 0.80 & 0.02 & 0.65 & 0.03 & 0.77 & 0.03 & 0.58 & 0.04 \\
\hline Dairy (high fat) $\dagger$ & $0 \cdot 10$ & 0.29 & 0.07 & 0.27 & 0.07 & $0 \cdot 15$ & 0.07 & 0.13 & 0.06 \\
\hline All Meat, Poultry, Eggs and Beans & 0.35 & 0.42 & 0.07 & 0.24 & 0.05 & 0.48 & 0.06 & 0.31 & 0.05 \\
\hline Meat (beef, pork, non-poultry lunch meat) + & 0.33 & 0.43 & 0.05 & 0.29 & 0.04 & 0.24 & 0.07 & 0.13 & 0.04 \\
\hline Poultry (all) $\dagger$ & 0.22 & 0.53 & 0.05 & 0.23 & 0.03 & 0.63 & 0.04 & 0.21 & 0.02 \\
\hline Poultry (low fat)t & 0.06 & 0.10 & 0.08 & 0.10 & 0.08 & 0.24 & 0.07 & 0.16 & 0.05 \\
\hline Eggst & 0.45 & 0.67 & 0.04 & 0.54 & 0.04 & 0.60 & 0.05 & 0.42 & 0.04 \\
\hline Nuts and seeds $†$ & 0.25 & 0.45 & 0.06 & 0.13 & 0.02 & 0.41 & 0.07 & 0.10 & 0.02 \\
\hline Fats, Oils and Sweetst & 0.21 & 0.32 & 0.07 & 0.15 & 0.04 & 0.11 & 0.08 & 0.06 & 0.04 \\
\hline Fats and oilst & 0.08 & 0.28 & 0.07 & 0.09 & 0.02 & 0.09 & 0.08 & 0.03 & 0.03 \\
\hline Sweets and desserts & 0.30 & 0.51 & 0.06 & 0.42 & 0.06 & 0.50 & 0.05 & 0.38 & 0.05 \\
\hline All chips, crackers, popcorn, pretzels $†$ & 0.19 & 0.39 & 0.06 & 0.32 & 0.06 & 0.41 & 0.07 & 0.23 & 0.04 \\
\hline Chips, high-fat crackers, popcornt & 0.01 & 0.08 & 0.08 & 0.09 & 0.08 & -0.04 & 0.08 & -0.03 & 0.05 \\
\hline Soda, Fruit Flavour Drinkt & 0.44 & 0.54 & 0.06 & 0.36 & 0.05 & 0.51 & 0.05 & 0.28 & 0.04 \\
\hline \multicolumn{10}{|l|}{ Nutrient } \\
\hline Total energy & 0.36 & 0.42 & 0.06 & 0.24 & 0.04 & \multicolumn{2}{|c|}{ _- } & _- & \\
\hline$\%$ Energy from carbohydrate & 0.37 & 0.48 & 0.06 & 0.37 & 0.06 & 0.48 & 0.06 & 0.34 & 0.05 \\
\hline Total carbohydrate $(\mathrm{g})$ & 0.30 & 0.39 & 0.07 & 0.21 & 0.04 & 0.45 & 0.06 & 0.30 & 0.05 \\
\hline Starch $(\mathrm{g})$ & 0.21 & 0.29 & 0.07 & 0.16 & 0.05 & 0.30 & 0.07 & 0.18 & 0.04 \\
\hline Fructose $(\mathrm{g})$ & 0.31 & 0.39 & 0.07 & 0.26 & 0.05 & 0.31 & 0.07 & 0.26 & 0.06 \\
\hline$\%$ Energy from protein & 0.35 & 0.44 & 0.06 & 0.48 & 0.08 & 0.42 & 0.06 & 0.46 & 0.07 \\
\hline Total protein $(\mathrm{g})$ & 0.31 & 0.38 & 0.07 & 0.23 & 0.05 & 0.42 & 0.06 & 0.41 & 0.07 \\
\hline$\%$ Energy from fat & 0.33 & 0.46 & 0.06 & 0.34 & 0.06 & 0.45 & 0.06 & 0.33 & 0.05 \\
\hline Total fat $(\mathrm{g})$ & 0.40 & 0.48 & 0.06 & 0.34 & 0.05 & 0.41 & 0.06 & 0.31 & 0.05 \\
\hline$\%$ Energy from SFA & 0.29 & 0.40 & 0.07 & 0.35 & 0.07 & 0.42 & 0.06 & 0.37 & 0.06 \\
\hline Saturated fat $(\mathrm{g})$ & 0.42 & 0.51 & 0.06 & 0.39 & 0.06 & 0.39 & 0.06 & 0.36 & 0.07 \\
\hline Fibre $(\mathrm{g})$ & 0.25 & 0.39 & 0.06 & 0.22 & 0.04 & 0.45 & 0.06 & 0.38 & 0.06 \\
\hline $\mathrm{Ca}(\mathrm{mq})$ & 0.16 & 0.28 & 0.07 & 0.16 & 0.04 & 0.19 & 0.07 & 0.14 & 0.05 \\
\hline $\mathrm{Mg}(\mathrm{mg})$ & 0.26 & 0.36 & 0.06 & 0.19 & 0.04 & 0.46 & 0.05 & 0.38 & 0.05 \\
\hline Cholesterol (mg) & 0.48 & 0.59 & 0.05 & 0.49 & 0.06 & 0.70 & 0.04 & 0.64 & 0.05 \\
\hline $\mathrm{Fe}(\mathrm{mg})$ & 0.11 & 0.18 & 0.08 & 0.11 & 0.05 & 0.31 & 0.06 & 0.28 & 0.06 \\
\hline Dietary folate equivalents $(\mu \mathrm{g})$ & 0.08 & 0.11 & 0.08 & 0.08 & 0.06 & 0.26 & 0.07 & 0.27 & 0.07 \\
\hline Vitamin $\mathrm{C}(\mathrm{mg})$ & 0.23 & 0.33 & 0.07 & 0.19 & 0.04 & 0.21 & 0.08 & 0.13 & 0.05 \\
\hline Linoleic acid (g) & 0.26 & 0.37 & 0.06 & 0.24 & 0.05 & 0.26 & 0.08 & 0.21 & 0.06 \\
\hline Linolenic acid (q) & 0.22 & 0.33 & 0.07 & 0.28 & 0.07 & 0.21 & 0.08 & 0.18 & 0.07 \\
\hline
\end{tabular}

†Denotes episodically consumed food ( $>10 \%$ of $24 \mathrm{~h}$ recalls did not report consumption).

only a very limited number of validated FFQ instruments for youth designed to be self-administered (or intervieweradministered) that assess a general $\operatorname{diet}^{(16,18,20,27-37)}$. Comparing with those studies that, like ours, utilized youth's self-report reveals that the SEARCH FFQ performed quite well in terms of validity, focusing on the crude Pearson's correlation coefficients for the sake of comparability ${ }^{(16,18,20,29,37)}$ (Pearson's $r_{\text {energy }}=0.35$ compared with range of $0 \cdot 21-0.43$ in previous studies; $r_{\text {protein }}=0.31$ compared with range of $0 \cdot 15-0 \cdot 31 ; r_{\text {total }}$ fat $=0.39$ compared with range of $0 \cdot 15-0 \cdot 48$ ). Our study also included an assessment of the instrument's reliability, as the FFQ was administered twice about one month apart. The SEARCH FFQ compared favourably with previous studies $^{(16,20,37,38)}\left(r_{\text {energy }}=0.50\right.$ compared with range of $0.30-0.49$ in previous studies; $r_{\text {protein }}=0.40$ compared with range of $0 \cdot 26-0.50 ; r_{\text {total fat }}=0.40$ compared with range $0 \cdot 41-0 \cdot 49)$. 
Table 4 Reliability of the FFQ: mean food group intake (servings/d) and mean daily nutrient consumption at baseline (FFQ1) and follow-up (FFQ2), with standard deviations, and intra-class correlation coefficients (ICC; $n$ 148); youth aged 10-24 years with type 1 diabetes, SEARCH for Diabetes in Youth Nutrition Ancillary Study

\begin{tabular}{|c|c|c|c|c|c|}
\hline & \multicolumn{2}{|c|}{ FFQ1 } & \multicolumn{2}{|c|}{ FFQ2 } & \multirow[b]{2}{*}{ ICC } \\
\hline & Mean & SD & Mean & SD & \\
\hline \multicolumn{6}{|l|}{ Food group } \\
\hline All Bread, Cereal, Rice and Pasta** & 2.6 & 1.3 & $2 \cdot 3$ & 1.2 & 0.44 \\
\hline Bread, cereal, rice and pasta (high fibre) ${ }^{\star}$ & $0 \cdot 1$ & $0 \cdot 2$ & 0.03 & $0 \cdot 1$ & 0.24 \\
\hline Bread, cereal, rice and pasta (low fibre) & $2 \cdot 6$ & 1.3 & $2 \cdot 3$ & 1.2 & 0.44 \\
\hline All Fruits and Vegetables ${ }^{\star \star}$ & $3 \cdot 2$ & $2 \cdot 0$ & $2 \cdot 6$ & 1.6 & 0.53 \\
\hline All Vegetables ${ }^{\star *}$ & $1 \cdot 7$ & 1.3 & $1 \cdot 3$ & $1 \cdot 2$ & 0.57 \\
\hline Vegetable (tomato) & 0.2 & 0.2 & 0.2 & 0.2 & 0.43 \\
\hline Vegetable (dark green, cruciferous) ${ }^{\star}$ & 0.5 & $0 \cdot 7$ & 0.4 & 0.5 & 0.50 \\
\hline Vegetable (deep yellow) & 0.2 & 0.3 & 0.2 & 0.4 & 0.57 \\
\hline Vegetable (potatoes) ${ }^{\star \star}$ & 0.5 & 0.5 & 0.4 & 0.3 & 0.40 \\
\hline Vegetable (other)* & 0.4 & 0.4 & 0.3 & 0.4 & 0.39 \\
\hline All Fruit ${ }^{\star}$ & 1.4 & 1.2 & 1.2 & 0.9 & 0.45 \\
\hline Fruit and fruit juice (citrus) & 0.3 & 0.6 & 0.3 & 0.5 & 0.37 \\
\hline Fruit and fruit juice (other) ${ }^{*}$ & $1 \cdot 1$ & 0.9 & 1.0 & 0.8 & 0.46 \\
\hline All Dairy** & $2 \cdot 0$ & 1.3 & 1.8 & $1 \cdot 1$ & 0.64 \\
\hline Dairy (low fat) & $1 \cdot 1$ & $1 \cdot 1$ & 1.0 & 0.9 & 0.71 \\
\hline Dairy (high fat) ${ }^{\star \star}$ & 0.9 & 0.7 & 0.7 & 0.6 & 0.44 \\
\hline All Meat, Fish, Poultry, Eggs and Beans ${ }^{\star *}$ & 2.5 & 1.5 & $2 \cdot 0$ & $1 \cdot 2$ & 0.45 \\
\hline Meat* & 1.4 & 1.0 & 1.2 & 0.9 & 0.34 \\
\hline Poultry (all) & 0.4 & 0.5 & 0.3 & 0.4 & 0.46 \\
\hline Poultry (high fat) & 0.3 & 0.5 & 0.3 & 0.4 & 0.45 \\
\hline Poultry (low fat) & 0.1 & $0 \cdot 1$ & 0.1 & $0 \cdot 1$ & 0.31 \\
\hline Fish and other seafood & 0.1 & 0.2 & 0.1 & 0.2 & 0.37 \\
\hline Dried beans & 0.1 & 0.3 & 0.1 & 0.2 & 0.45 \\
\hline Eggs $^{*}$ & 0.4 & 0.4 & 0.3 & 0.3 & 0.41 \\
\hline Nuts and seeds & 1.3 & $2 \cdot 2$ & 1.3 & 2.5 & 0.40 \\
\hline Fats, Oils and Sweets** & 4.3 & $2 \cdot 7$ & 3.4 & $2 \cdot 4$ & 0.40 \\
\hline Fats and oils* & 2.9 & $2 \cdot 2$ & $2 \cdot 2$ & $2 \cdot 1$ & 0.38 \\
\hline Sweets and desserts* & 1.4 & 1.0 & 1.2 & 0.9 & 0.48 \\
\hline All Chips, Crackers, Popcorn, Pretzels* & 0.6 & 0.6 & 0.5 & 0.5 & 0.43 \\
\hline Chips, high-fat crackers, popcorn & 0.4 & 0.4 & 0.4 & 0.3 & 0.43 \\
\hline Sweetened Coffee and Tea & 0.2 & 0.5 & 0.1 & 0.3 & 0.61 \\
\hline Soda, Fruit Flavour Drink & 0.7 & $1 \cdot 1$ & 0.6 & 0.9 & 0.54 \\
\hline \multicolumn{6}{|l|}{ Nutrient } \\
\hline Total energy $(\mathrm{kJ})^{\star *}$ & 7021 & 3017 & 5925 & 2322 & 0.47 \\
\hline Total energy $(\mathrm{kcal})^{\star \star}$ & 1678 & 721 & 1416 & 555 & 0.47 \\
\hline$\%$ Energy from carbohydrate & 46 & 8 & 47 & 8 & 0.46 \\
\hline Total carbohydrate $(\mathrm{g})^{\star \star}$ & $193 \cdot 7$ & $91 \cdot 0$ & $165 \cdot 0$ & $69 \cdot 0$ & 0.53 \\
\hline Starch $(g)^{\star \star}$ & 83.6 & 38.7 & $69 \cdot 3$ & $29 \cdot 1$ & 0.47 \\
\hline Fructose $(\mathrm{g})$ & $21 \cdot 8$ & $16 \cdot 2$ & $19 \cdot 0$ & $13 \cdot 8$ & 0.52 \\
\hline$\%$ Energy from protein & 15 & 2 & 15 & 3 & 0.41 \\
\hline Total protein $(\mathrm{g})^{\star \star}$ & 63.7 & $29 \cdot 1$ & $52 \cdot 9$ & $23 \cdot 1$ & 0.41 \\
\hline$\%$ Energy from fat & 40 & 6 & 40 & 6 & 0.42 \\
\hline Total fat $(\mathrm{g})^{\star \star}$ & $74 \cdot 6$ & $33 \cdot 6$ & $62 \cdot 7$ & $27 \cdot 1$ & 0.42 \\
\hline$\%$ Energy from SFA & 14 & 2 & 14 & 2 & 0.37 \\
\hline Saturated fat $(\mathrm{g})^{\star \star}$ & $25 \cdot 7$ & 11.9 & 21.3 & $9 \cdot 1$ & 0.40 \\
\hline Fibre $(g)^{\star *}$ & $12 \cdot 6$ & $6 \cdot 2$ & $10 \cdot 5$ & 5.5 & 0.52 \\
\hline $\mathrm{Ca}(\mathrm{mg})^{\star \star}$ & 723.4 & 475.8 & 614.0 & 385.5 & 0.38 \\
\hline $\operatorname{Mg}(m g)^{\star \star}$ & $211 \cdot 2$ & 101.6 & $180 \cdot 8$ & 91.0 & 0.49 \\
\hline Cholesterol $(\mathrm{mg})^{\star \star}$ & $249 \cdot 2$ & $141 \cdot 7$ & 197.6 & 115.9 & 0.43 \\
\hline $\mathrm{Fe}(\mathrm{mg})^{\star \star}$ & 11.5 & 5.5 & 9.4 & 4.3 & 0.47 \\
\hline Dietary folate equivalents $(\mu \mathrm{g})^{\star *}$ & 374.9 & $177 \cdot 5$ & $316 \cdot 4$ & $146 \cdot 2$ & 0.53 \\
\hline Vitamin C $(\mathrm{mg})^{\star \star}$ & 74.8 & 55.0 & $62 \cdot 0$ & 47.6 & 0.55 \\
\hline Linoleic acid $(\mathrm{g})^{\star}$ & $10 \cdot 7$ & 5.6 & $9 \cdot 4$ & $5 \cdot 1$ & 0.42 \\
\hline Linolenic acid $(\mathrm{g})^{\star}$ & 1.0 & 0.5 & 0.9 & 0.4 & 0.44 \\
\hline
\end{tabular}

${ }^{*} P<0.05,{ }^{*} P<0.01$ for $t$-test comparison of mean of FFQ1 and FFQ2.

To the best of our knowledge, only one other evaluation of the relative validity of the Block Kids Questionnaire (completed by the youths themselves) has been published ${ }^{(18)}$. Other reports on this instrument have relied on the parental report ${ }^{(39)}$, compared only mean intakes ${ }^{(40)}$ or have been solely presented at conferences ${ }^{(25)}$. In a sample of eighty-three youth aged 10-17 years (thirty-one of whom had type 2 diabetes), Cullen et al. ${ }^{(18)}$ reported energy-adjusted and measurement error-adjusted correlation coefficients ranging from 0.29 for fibre to 0.69 for percentage of energy from carbohydrates and from -0.03 for grains to 0.74 for dairy. Comparison of the correlation 
coefficients for the SEARCH FFQ with those published by Cullen $e t ~ a l .{ }^{(18)}$ reveals that with respect to nutrients, our study found a similar range of correlations ( 0.19 for $\mathrm{Ca}$ to 0.70 for cholesterol), with a better relative validity for fibre $(0.45$ in our study $v .0 .29$ in Cullen et al.) and cholesterol $(0.70 v .0 .58)$, but lower correlations for percentage of energy from carbohydrates $(0.48 v .0 .69)$ and percentage of energy from protein $(0.42 v .0 .55)$. Furthermore, for the three food groups that were directly comparable between the two studies, the correlation coefficients for vegetables on the SEARCH FFQ were better than in Cullen et al. (0.56 $v .0 \cdot 17)$ and dairy was similarly high $(0.63 v .0 .74)$. Our correlation for bread, cereal, rice and pasta was also somewhat higher than in Cullen et al. $(0.26 v .-0.03)$. While Cullen et al. concluded that in their sample, the Block Kids Questionnaire had 'validity for some nutrients, but not [for] most food groups ${ }^{(18)}$, we reached a different conclusion for the SEARCH FFQ. While there is clearly need for improvement for a few select food groups (i.e. the bread, cereal, rice and pasta group, especially the high-fibre versions of these foods; chips, high-fat crackers and popcorn; low-fat poultry; high-fat dairy), it is reassuring that many of the food groups encouraged by dietary guidelines demonstrated good relative validity. These included all fruits and vegetables, vegetables specifically, low-fat dairy and dairy in aggregate, and poultry in aggregate. Sugar-sweetened beverages, a food group specifically discouraged in dietary guidelines, was also measured with reasonable validity.

Aside from the fact that Cullen et al. ${ }^{(18)}$ evaluated the original Block Kids Questionnaire while our study evaluated the SEARCH FFQ, there are several methodological differences between the studies. Unlike our study, Cullen et $a l .{ }^{(18)}$ relied on two days of $24 \mathrm{~h}$ dietary recalls and did not accommodate the episodic nature of the consumption of individual food groups. Furthermore, Cullen et al. ${ }^{(18)}$ relied on using an estimate of within-subject variability in consumption to perform measurement error adjustment of the correlation between food recalls and FFQ, and did not model systematic bias. This estimate of within-subject variability is best when the food recall data are approximately normally distributed, which is not the case with episodically consumed foods. Furthermore, with three days of $24 \mathrm{~h}$ recall, a participant is more likely to have at least two consumption days, which are needed on a subset of participants to partition within-person random error from the variability of usual intake.

While statistical methods to adjust dietary intake for measurement error have long been used in nutritional epidemiology ${ }^{(12-15)}$, the integration into analyses of the validity of dietary assessment instruments is still evolving. Unlike the Spearman or Pearson correlation coefficients that have been used traditionally to evaluate validity, either with or without correction for measurement error ${ }^{(16,41,42)}$, the model-estimated correlation coefficient adjusts for withinperson variability in intake in the $24 \mathrm{~h}$ recalls. The NCI method used in the current study appropriately models episodically consumed foods, adjusts for measurement error, transforms amount data to approximate normality, and models the ratio of usual intake of nutrients to energy by jointly modelling dietary components and energy. This method has been applied to food group validation in recent studies of adults ${ }^{(21)}$. Validation efforts in samples of children and youth have either not included any consideration of measurement error ${ }^{(37,41-45)}$ or applied a more simplified approach for daily consumed dietary components with consideration only of random error ${ }^{(15,16,19,20)}$.

In addition to the model-based correlation coefficients, we estimated attenuation factors, which express the amount of bias in an exposure-disease relationship. The smaller the attenuation factor (i.e. the closer to zero), the more biased is the exposure-disease relationship. Midthune et al. ${ }^{(21)}$ suggest that for food groups (and nutrients) with attenuation factors of 0.2 and greater, measurement error modelling can be a viable solution. However, for attenuation factors $<0 \cdot 2$, caution is advised because deattenuation may result in unreliable estimates. Our results indicate that for some nutrients and food groups there is the potential for a considerable amount of bias. For instance, without consideration of measurement error modelling, the coefficient describing the relationship of FFQ-based dairy intake to disease or risk factor outcomes would be reduced by $43 \%$.

Our study has a number of limitations. Unlike most FFQ used for adults which query the past year ${ }^{(8,46)}$, the SEARCH FFQ asks about dietary intake in the preceding week, because most youth will not be able to cognitively integrate dietary intake over a whole year. Compared with studies of adults ${ }^{(21,46)}$, validation efforts in youth - including our study - found somewhat weaker correlations, which is likely due both to this reduced time frame and to younger respondents having more difficulties with the recall ${ }^{(26)}$. When we explored the role of age, like others we too found that relative validity was slightly higher in the older age group of the youth ${ }^{(18,37)}$. Because of the more limited list of items compared with an adult FFQ and the shorter time window in which usual intake was assessed, administering the SEARCH FFQ yielded a higher proportion of nonconsumption of certain food groups, which in turn limited the ability to create and evaluate very finely classified food groups. In addition, we were unable to adjust for true nonconsumers in the present study, which requires a large sample size of at least four $24 \mathrm{~h}$ recalls; however, the true predicted intakes for non-consumers were close to zero. Similar to other studies, we relied on $24 \mathrm{~h}$ dietary recalls as the reference instrument under the assumption that they provide an unbiased estimate of true intake, even though it has been shown that the $24 \mathrm{~h}$ recall is somewhat biased for protein, energy and protein density in adults ${ }^{(47,48)}$. To the extent that the assumption of unbiasedness is violated, this may lead to some overestimation of the correlations and attenuation factors ${ }^{(47,48)}$. 
The valid and reliable assessment of dietary intake in youth with diabetes is of paramount importance both for research and practice. Because of the emphasis on medical nutrition therapy and carbohydrate counting $^{(16,18,20,26,29,37)}$, youth with type 1 diabetes may have a heightened awareness of their diet and may potentially perform better on validity or reliability assessment. In comparison to other self-reported FFQ for youth, the SEARCH FFQ performed quite well both in terms of relative validity and reliability. A small number of food groups clearly need to be better assessed in future modifications of this instrument, including fats and oils and the bread, cereal, rice and pasta group, particularly with respect to high-fibre foods. In addition, the $7 \mathrm{~d}$ recall period necessary for children may be a significant limitation, and researchers may wish to consider replicating the FFQ or collecting supplemental dietary data to overcome this limitation. The present study furthermore illustrated the utility of measurement error modelling in the context of validating a dietary assessment instrument. While there is clearly some room for improvement in our questionnaire, our findings suggest that, with a few exceptions, the SEARCH FFQ will be useful in estimating associations between food group- or nutrient-based dietary exposures and outcomes in youth with type 1 diabetes in the SEARCH for Diabetes in Youth Study.

\section{Acknowledgements}

Acknowledgements: The SEARCH for Diabetes in Youth Study is indebted to the many youth and their families, and their health-care providers, whose participation made this study possible. The authors would also like to acknowledge the staff at the University of North Carolina Nutrition Obesity Research Center - Diet, Physical Activity and Body Composition Core (DK-56350) who conducted the $24 \mathrm{~h}$ dietary recall interviews. Financial support: The SEARCH Nutrition Ancillary Study was funded by the National Institutes of Health (NIH), National Institute of Diabetes and Digestive and Kidney Diseases (NIDDK) (Principal Investigator E.J.M.-D., grant number 5R01DK077949). The SEARCH for Diabetes in Youth Study is funded by the Centers for Disease Control and Prevention (PA numbers 00097, DP-05069 and DP-10-001) and supported by the NIDDK (site contract numbers: Kaiser Permanente Southern California, U48/CCU919219, U01 DP000246 and U18DP002714; University of Colorado Denver, U48/CCU819241-3, U01 DP000247 and U18DP000247-06A1; Kuakini Medical Center, U58CCU919256 and U01 DP000245; Children's Hospital Medical Center (Cincinnati), U48/CCU519239, U01 DP000248 and 1U18DP002709; University of North Carolina at Chapel Hill, U48/CCU419249, U01 DP000254 and U18DP002708-01; University of Washington School of Medicine, U58/CCU019235-4, U01 DP000244 and U18DP002710-01; and Wake Forest University School of
Medicine, U48/CCU919219, U01 DP000250 and 200-201035171). The contents of this paper are solely the responsibility of the authors and do not necessarily represent the official views of the NIKKD or the NIH. The funders had no role in the design, analysis or writing of this article. Conflict of interest: None. Authorship: A.D.L. conceptualized the manuscript, interpreted the data, and drafted and revised the manuscript. J.L.C. conducted the statistical analyses and contributed to the drafting and revision of the manuscript. J.A.T. provided guidance to the statistical analyses and contributed to interpreting the data, drafting and revision of the manuscript. S.C.C., A.T.M., R.A.B. and E.J.M.-D. contributed to the interpretation of the data and the revision of the manuscript. Ethics of human subject participation: The SNAS protocol was reviewed and approved by the institutional review boards of all participating institutions. The SNAS study did not recruit additional participants, but collected data on infant feeding and nutrient biomarkers from youth enrolled in SEARCH.

\section{References}

1. DIAMOND Project Group (2006) Incidence and trends of childhood type 1 diabetes worldwide 1990-1999. Diabet Med 23, 857-866.

2. Mayer-Davis EJ, Dabelea D, Talton J et al. (2012) Increase in prevalence of type 1 diabetes from the SEARCH for Diabetes in Youth Study: 2001 to 2009. Presented at the American Diabetes Association 72nd Scientific Sessions, Philadelphia, PA, USA, 8-12 June 2012.

3. Lawrence JM, Bell RA, Dabelea D et al. (2012) Trends in incidence of type 1 diabetes among non-Hispanic white youth in the US, 2002-2009. Presented at the American Diabetes Association 72nd Scientific Sessions, Philadelphia, PA, USA, 8-12 June 2012.

4. SEARCH Study Group (2004) SEARCH for Diabetes in Youth: a multicenter study of the prevalence, incidence and classification of diabetes mellitus in youth. Control Clin Trials 25, 458-471.

5. Silverstein J, Klingensmith G, Copeland K et al. (2005) Care of children and adolescents with type 1 diabetes: a statement of the American Diabetes Association. Diabetes Care 28, 186-212.

6. Mayer-Davis EJ, Nichols M, Liese AD et al. (2006) Dietary intake among youth with diabetes: the SEARCH for Diabetes in Youth Study. J Am Diet Assoc 106, 689-697.

7. Liu LL, Lawrence JM \& Davis C et al. (2010) Prevalence of overweight and obesity in youth with diabetes in USA: the SEARCH for Diabetes in Youth Study. Pediatr Diabetes 11, 4-11.

8. Mayer-Davis EJ, Vitolins MZ, Carmichael SL et al. (1999) Validity and reproducibility of a food frequency interview in a multi-cultural epidemiology study. Ann Epidemiol 9, 314-324.

9. Stram DO, Hankin JH, Wilkens LR et al. (2000) Calibration of the dietary questionnaire for a multiethnic cohort in Hawaii and Los Angeles. Am J Epidemiol 151, 358-370.

10. Kumanyika SK, Mauger D, Mitchell DC et al. (2003) Relative validity of food frequency questionnaire nutrient estimates in the Black Women's Health Study. Ann Epidemiol 13, 111-118.

11. Flagg EW, Coates RJ, Calle EE et al. (2000) Validation of the American Cancer Society Cancer Prevention Study II Nutrition Survey Cohort Food Frequency Questionnaire. Epidemiology 11, 462-468. 
12. Beaton GH, Milner J, Corey P et al. (1979) Sources of variance in 24-hour dietary recall data: implications for nutrition study design and interpretation. Am J Clin Nutr 32, $2546-2559$

13. Rosner B, Spiegelman D \& Willett WC (1990) Correction of logistic regression relative risk estimates and confidence intervals for measurement error: the case of multiple covariates measured with error. Am J Epidemiol 132, 734-745.

14. Freedman LS, Carroll RJ \& Wax Y (1991) Estimating the relation between dietary intake obtained from a food frequency questionnaire and true average intake. $A m J$ Epidemiol 134, 310-320.

15. Willett W (1998) Nutritional Epidemiology. New York: Oxford University Press.

16. Rockett HRH, Breitenbach M, Frazier AL et al. (1997) Validation of a youth/adolescent food frequency questionnaire. Prev Med 26, 808-816.

17. Millen AE, Midthune D, Thompson FE et al. (2006) The National Cancer Institute diet history questionnaire: validation of pyramid food servings. Am J Epidemiol 163, 279-288.

18. Cullen KW, Watson K \& Zakeri I (2008) Relative reliability and validity of the Block Kids Questionnaire among youth aged 10 to 17 years. J Am Diet Assoc 108, 862-866.

19. Fumagalli F, Pontes MJ, Sartorelli DS et al. (2008) Validation of a food frequency questionnaire for assessing dietary nutrients in Brazilian children 5 to 10 years of age. Nutrition 24, 427-432.

20. Watson JF, Collins CE, Sibbritt DW et al. (2009) Reproducibility and comparative validity of a food frequency questionnaire for Australian children and adolescents. Int J Behav Nutr Phys Act 6, 62

21. Midthune D, Schatzkin A, Subar AF et al. (2011) Validating an FFQ for intake of episodically consumed foods: application to the National Institutes of Health-AARP Diet and Health Study. Public Health Nutr 14, 1212-1221.

22. Tooze JA, Midthune D, Dodd KW et al. (2006) A new statistical method for estimating the usual intake of episodically consumed foods with application to their distribution. J Am Diet Assoc 106, 1575-1587.

23. Kipnis V, Midthune D, Buckman DW et al. (2009) Modeling data with excess zeros and measurement error: application to evaluating relationships between episodically consumed foods and health outcomes. Biometrics 65, 1003-1010.

24. Zhang S, Krebs-Smith SM, Midthune D et al. (2011) Fitting a bivariate measurement error model for episodically consumed dietary components. Int J Biostat 7, 1 .

25. Block G, Murphy M, Roullet JB et al. (2000) Pilot validation of a FFQ for children 8-10 years. Presented at the Fourth International Conference on Dietary Assessment Methods, Tucson, AZ, USA, 17-20 September 2000.

26. McPherson RS, Hoelscher D, Alexander M et al. (2000) Dietary assessment methods among school-aged children: validity and reliability. Prev Med 31, S11-S33.

27. Knuiman JT, Rasanen L, Ahola M et al. (1987) The relative validity of reports of food intake of Dutch and Finnish boys aged 8 and 9 years. J Am Diet Assoc 87, 303-307.

28. Blom L, Lundmark K, Dahlquist G et al. (1989) Estimating children's eating habits. Validity of a questionnaire measuring food frequency compared to a 7-day record. Acta Paediatr Scand 78, 858-864.

29. Jenner DA, Neylon K, Croft S et al. (1989) A comparison of methods of dietary assessment in Australian children aged 11-12 years. Eur J Clin Nutr 43, 663-673.

30. Byers T, Trieber F, Gunter E et al. (1993) The accuracy of parental reports of their children's intake of fruits and vegetables: validation of a food frequency questionnaire with serum levels of carotenoids and vitamins $\mathrm{C}, \mathrm{A}$, and $\mathrm{E}$. Epidemiology 4, 350-355.
31. Hammond J, Nelson M, Chinn S et al. (1993) Validation of a food frequency questionnaire for assessing dietary intake in a study of coronary heart disease risk factors in children. Eur J Clin Nutr 47, 242-250.

32. Domel SB, Thompson WO, Baranowski T et al. (1994) How children remember what they have eaten. J Am Diet Assoc 94, 1267-1272.

33. Baranowski T, Smith M, Baranowski J et al. (1997) Low validity of a seven-item fruit and vegetable food frequency questionnaire among third-grade students. J Am Diet Assoc 97, 66-68.

34. Champagne CM, Baker NB, DeLany JP et al. (1998) Assessment of energy intake underreporting by doubly labeled water and observations on reported nutrient intakes in children. J Am Diet Assoc 98, 426-433.

35. Green TJ, Allen OB \& O'Connor DL (1998) A three-day weighed food record and a semiquantitative food-frequency questionnaire are valid measures for assessing the folate and vitamin B-12 intakes of women aged 16 to 19 years. J Nutr 128, 1665-1671.

36. Taylor RW \& Goulding A (1998) Validation of a short food frequency questionnaire to assess calcium intake in children aged 3 to 6 years. Eur J Clin Nutr 52, 464-465.

37. Preston AM, Palacios C, Rodriguez CA et al. (2011) Validation and reproducibility of a semi-quantitative food frequency questionnaire for use in Puerto Rican children. $P R$ Health Sci J 30, 58-64.

38. Rockett HR, Wolf AM \& Colditz GA (1995) Development and reproducibility of a food frequency questionnaire to assess diets of older children and adolescents. J Am Diet Assoc 95, 336-340.

39. Marshall TA, Eichenberger Gilmore JM, Broffitt B et al. (2003) Relative validation of a beverage frequency questionnaire in children ages 6 months through 5 years using 3-day food and beverage diaries. J Am Diet Assoc 103, 714-720

40. Smith C \& Fila S (2006) Comparison of the Kid's Block Food Frequency Questionnaire to the 24-hour recall in urban Native American youth. Am J Hum Biol 18, 706-709.

41. Vereecken CA \& Maes L (2003) A Belgian study on the reliability and relative validity of the Health Behaviour in School-Aged Children food-frequency questionnaire. Public Health Nutr 6, 581-588.

42. Kobayashi T, Kamimura M, Imai S et al. (2011) Reproducibility and validity of the food frequency questionnaire for estimating habitual dietary intake in children and adolescents. Nutr J 10, 27.

43. Shatenstein B, Amre D, Jabbour M et al. (2010) Examining the relative validity of an adult food frequency questionnaire in children and adolescents. J Pediatr Gastroenterol Nutr $\mathbf{5 1}$, 645-652.

44. Stiegler P, Sausenthaler S, Buyken AE et al. (2010) A new FFQ designed to measure the intake of fatty acids and antioxidants in children. Public Health Nutr 13, 38-46.

45. Zemel BS, Carey LB, Paulhamus DR et al. (2010) Quantifying calcium intake in school age children: development and validation of the Calcium Counts! food frequency questionnaire. Am J Hum Biol 22, 180-186.

46. Thompson FE, Kipnis V, Midthune D et al. (2008) Performance of a food-frequency questionnaire in the US NIH-AARP (National Institutes of Health-American Association of Retired Persons) Diet and Health Study. Public Health Nutr 11, 183-195.

47. Kipnis V, Subar AF, Midthune D et al. (2003) Structure of dietary measurement error: results of the OPEN biomarker study. Am J Epidemiol 158, 14-21.

48. Kipnis V, Midthune D, Freedman LS et al. (2001) Empirical evidence of correlated biases in dietary assessment instruments and its implications. Am J Epidemiol 153, 394-403. 